\title{
HUBUNGAN MUTU PELAYANAN KESEHATAN DENGAN KEPUASAN PASIEN RAWAT JALAN DI PUSKESMAS BATUMANDI KABUPATEN BALANGAN TAHUN 2021
}

\author{
RELATIONSHIP OF QUALITY OF HEALTH SERVICES WITH OUTPATIENT \\ PATIENT SATISFACTION AT BATUMANDI PUSKESMAS, BALANGAN REGENCY \\ IN 2021
}

\section{Fakhsiannor}

Fakultas Kesehatan Masyarakat, Universitas Islam Kalimantan (UNISKA) MAB Banjarmasin Jl. Adhyaksa. No.2. Kota Banjarmasin, Kalimantan Selatan. Indonesia Email : fakhsiannor063@gmail.com

\begin{abstract}
Based on the recapitulation data of outpatients at the Batumandi Health Center for the last 3 years from 2019 to 2021 the number of outpatients at the Batumandi Health Center has decreased. The recapitulation data of outpatients at the Batumandi Health Center in 2019 amounted to 13,733 people, in 2020 there were 7,814 people and in 2021, from January to May, there were 2,267 people. The purpose of this study was to determine the relationship between the quality of health services and outpatient satisfaction at the Batumandi Health Center, Balangan Regency in 2021. This type of research used quantitative research with analytical survey research methods with a cross sectional approach. The population in this study were outpatients from January to May as many as 2,267 people with a sample of 96 respondents. The results showed that there were 51 respondents (53.1\%) who stated good reliability, 56 respondents $(58.3 \%)$ who stated good responsiveness, 58 respondents (60.4\%) who stated assurance) not good, 60 respondents (62.5\%) stated that empathy (attention) was not good and 63 respondents (62.5\%) stated that tangible (physical evidence/direct evidence) was not good. From the research results, it can be concluded that there is a relationship between reliability (reliability) with $p$-value $=0.001$, responsiveness (responsiveness) with $p$-value $=0.006$, assurance (guarantee) with $p$-value $=0.008$, empathy (attention) with $p$-value $=0.009$, tangible (physical evidence / direct evidence) with $p$-value $=0.001$ with patient satisfaction .
\end{abstract}

Keywords : Reliability; responsiveness; assurance; empath; tangible with patient satisfaction

\section{ABSTRAK}

Data rekapitulasi pasien rawat jalan di Puskesmas Batumandi selama 3 tahun terakhir dari tahun 2019 hingga 2021 jumlah pasien rawat jalan di Puskesmas Batumandi mengalami penurunan. Data rekapitulasi pasien rawat jalan di Puskesmas Batumandi tahun 2019 berjumlah sebanyak 13.733 jiwa, tahun 2020 berjumlah 7.814 jiwa dan tahun 2021 yang terhitung dari bulan Januari hingga Mei berjumlah 2.267 jiwa. Tujuan penelitian ini untuk mengetahui hubungan mutu pelayanan kesehatan dengan kepuasan pasien rawat jalan di Puskesmas Batumandi Kabupaten Balangan tahun 2021. Jenis penelitian ini menggunakan penelitian kuantitatif dengan metode penelitian survey analitik dengan pendekatan cross sectional. Populasi dalam penelitian adalah pasien rawat jalan dari bulan Januari hingga Mei sebanyak 2.267 jiwa dengan sampel 96 responden. Hasil penelitian menunjukkan bahwa ada 51 responden $(53,1 \%)$ yang menyatakan reliability (kehandalan) baik, 56 responden $(58,3 \%)$ yang menyatakan responsiveness (ketanggapan) baik, 58 responden $(60,4 \%)$ yang menyatakan assurance (jaminan) tidak baik, 60 responden (62,5\%) yang menyatakan empathy (perhatian) tidak baik dan 63 responden (62,5\%) yang menyatakan tangible (bukti fisik/bukti langsung) tidak baik. Dari hasil penelitian didapatkan kesimpulan bahwa ada hubungan antara reliability (kehandalan) dengan $p$-value $=0,001$, responsiveness (ketanggapan) dengan $p$ value $=0,006$, assurance (jaminan) dengan $p$-value $=0,008$, empathy (perhatian) dengan $p$ value $=0,009$, tangible (bukti fisik/bukti langsung) dengan $p$-value $=0,001$ dengan kepuasan pasien.

Kata Kunci : Kehandalan; Ketanggapan; Jaminan; Perhatian; Bukti fisik dengan kepuasan 


\section{PENDAHULUAN}

Pembangunan kesehatan merupakan bagian integral dari Pembangunan Nasional sebagaimana tercantum dalam Rencana Pembangunan Jangka Menengah Nasional (RPJMN) Tahun 2020-2024. Pembangunan kesehatan bertujuan untuk meningkatkan kesadaran, kemauan dan kemampuan hidup sehat bagi setiap orang, agar tercapai derajat kesehatan yang setinggi-tingginya baik fisik, mental dan sosial melalui upaya promotif, preventif, kuratif dan rehabilitatif. Pembangunan kesehatan diselenggarakan berdasarkan perikemanusiaan, pemberdayaan masyarakat, kemandirian secara adil dan merata, melalui pendekatan life cycle (1).

Kepuasan diartikan sebagai ungkapan perasaan masyarakat yang muncul setelah membandingkan antara persepsi terhadap kinerja suatu produk. Menurut Azwar (1997) dalam Bustami (2011) (2), menyebutkan bahwa mutu pelayanan kesehatan adalah terpenuhinya derajat kebutuhan masyarakat atau perorangan terhadap asuhan kesehatan yang sesuai dengan standar profesi yang baik dengan pemanfaatan sumber daya secara wajar, efisien dan efektif dalam keterbatasan secara aman dan memuaskan pelanggan sesuai dengan norma dan etika yang baik.

Salah satu indikator keberhasilan pelayanan kesehatan adalah kepuasaan pasien terhadap pelayanan kesehatan yang didapatkan. Menurut Nursalam (2014) (3), dalam konsep mutu layanan yang berkaitan dengan kepuasan pasien di tentukan oleh lima unsur yang biasa di kenal dengan istilah mutu layanan "SERVQUAL" (reliabilty, responsiveness, assurance, empathy dan tangible). Seiring dengan kemajuan teknologi dan pertambahan jumlah penduduk yang selalu meningkat seiap tahun nya membuat tuntutan masyarakat semakin tinggi dalam hal pelayanan, setiap unit penyelenggara pelayanan publik dituntut untuk memenuhi harapan masyarakat dalam melakukan pelayanan. Salah satu pelayanan publik di Indonesia adalah pelayanan dibidang kesehatan. Dalam memberikan pelayanan kesehatan Puskesmas dihadapkan pada beberapa tantangan dalam hal sumber daya manusia dan peralatan kesehatan yang semakin canggih serta pertambahan jenis penyakit baru (4).

Pusat kesehatan masyarakat (Puskesmas) merupakan salah satu komponen dalam sistem kesehatan masyarakat, Puskesmas berfungsi memberikan pelayanan secara paripurna melalui upaya kuratif, rehabilitatif, promotif dan preventif. Puskesmas sebagai sarana pelayanan kesehatan terdepan bertanggung jawab dalam menyelenggarakan pelayanan kesehatan dengan mutu yang baik dengan biaya yang terjangkau oleh masyarakat. Dalam rangka meningkatkan kunjungan pasien ke Puskesmas maka Puskesmas harus mampu menampilkan dan memberikan pelayanan kesehatan yang berkualitas dan bermutu sehingga mampu memberikan kepuasan bagi pasien (5).

Puskesmas Batumandi memiliki tenaga kesehatan yang berjumlah 37 dan memiliki pelayanan kesehatan di antaranya pelayanan kesehatan umum, pelayanan kesehatan lansia, pelayanan kesehatan gigi, pelayanan kesehatan ibu dan anak, pelayanan kesehatan anak, pelayanan obat, laboratorium, konsultasi gizi, klinik sanitasi, dan pelayanan kesehatan peduli remaja. Berdasarkan data rekapitulasi pasien rawat jalan di Puskesmas Batumandi selama 3 tahun terakhir yaitu dari tahun 2019 hingga 2021 jumlah pasien rawat jalan di Puskesmas Batumandi mengalami penurunan. Data rekapitulasi pasien rawat jalan di Puskesmas Batumandi tahun 2019 berjumlah sebanyak 13.733 jiwa, tahun 2020 berjumlah berjumlah 7.814 jiwa dan tahun 2021 yang terhitung dari bulan Januari hingga Mei berjumlah 2.267 jiwa dengan jumlah pasien pada bulan Januari sebanyak 408 jiwa, Februari sebanyak 505 jiwa, Maret sebanyak 625 jiwa, April sebanyak 584 jiwa dan Mei sebanyak 145 jiwa. Dalam hal ini juga terjadi penurunan jumlah pesien rawat jalan pada bulan April dan Mei.

Berdasarkan studi pendahulan yang dilakukan di Puskesmas Batumandi, dari hasil wawancara yang dilakukan dengan 8 orang responden yang melakukan pengobatan di Puskesmas Batumandi 3 diantaranya menyatakan puas terhadap pelayanan yang diberikan, namun 5 diantaranya menyatakan tidak puas terhadap pelayanan yang diberikan salah satu alasannya adalah karena ruang tunggu pasien yang berada diluar ruangan sehingga mereka mengeluh kepanasan pada saat menunggu, kurangnya media informasi yang tersedia di Puskesmas Batumandi membuat pasien sulit mencari informasi baik itu untuk informasi ruangan atau ke tahap pelayanan yang dituju, dan juga lahan parkir yang masih seadanya serta adanya beberapa petugas 
kesehatan yang kurang ramah dalam melakukan pelayanan. Berdasarakan uraian diatas maka peneliti tertarik untuk melakukan penelitian dengan judul "Hubungan Mutu Pelayanan Kesehatan dengan Kepuasan Pasien Rawat Jalan di Puskesmas Batumandi Kabupaten Balangan Tahun 2021".

\section{BAHAN DAN METODE}

Penelitian ini merupakan jenis penelitian kuantitatif dengen metode penelitian survey analitik dengan menggunakan pendekatan cross sectional (studi potong lintang). Desain penelitian survey analitik cross sectional antara variabel bebas dan variabel terikat pada suatu periode tertentu.

\section{HASIL DAN PEMBAHASAN}

Tabel 1. Karakteristik Responden

\begin{tabular}{lll}
\hline Variabel & $\mathbf{n}$ & $\mathbf{0}$ \\
\hline Umur & & \\
17-25 Tahun & 20 & 20,8 \\
26-35 Tahun & 26 & 27,1 \\
36-45 Tahun & 28 & 29,2 \\
46-55 Tahun & 13 & 13,5 \\
56-65 Tahun & 8 & 8,3 \\
>65 Tahun & 1 & 1,0 \\
Jenis Kelamin & & \\
Laki-laki & 20 & 20,8 \\
Perempuan & 76 & 79,2 \\
Pendidikan & & \\
Tidak Sekolah & 1 & 1 \\
Tamat SD/Sederajat & 35 & 36,5 \\
Tamat SMP/Sederajat & 27 & 28,1 \\
Tamat SMA/Sederajat & 24 & 25 \\
Perguruan Tinggi & 9 & 9,4 \\
Pekerjaan & & \\
Bekerja & 46 & 47,9 \\
Tidak Bekerja & 50 & 52,1 \\
Total & $\mathbf{9 6}$ & $\mathbf{1 0 0}$ \\
\hline Sumber: Data Priner, 2021 & & \\
\hline
\end{tabular}

Sumber : Data Primer, 2021
Analisis Univariat

Tabel 2. Distribusi Frekuensi

\begin{tabular}{lcc}
\hline \multicolumn{1}{c}{ Variabel } & $\mathbf{n}$ & $\%$ \\
\hline Realibility & & \\
Baik & 51 & 53,1 \\
Tidak Baik & 45 & 46,9 \\
$\begin{array}{l}\text { Responsiveness } \\
\text { Baik }\end{array}$ & 56 & 58,3 \\
Tidak Baik & 40 & 41,7 \\
Assurance & & \\
Baik & 38 & 39,6 \\
Tidak Baik & 58 & 60,4 \\
Empathy & & \\
Baik & 36 & 37,5 \\
Tidak Baik & 60 & 62,5 \\
Tangible & & \\
Baik & 33 & 34,4 \\
Tidak Baik & 63 & 65,6 \\
Total & $\mathbf{9 6}$ & $\mathbf{1 0 0}$ \\
\hline
\end{tabular}

Sumber : Data Primer, 2021 


\section{Analisis Bivariat}

Tabel 3. Hubungan Realibilty, Responseivenes, Assurance, Empathy dan Tangible dengan Kepuasan Pasien Rawat Jalan di Puskesmas Batumandi Kabupaten Balangan Tahun 2021

\begin{tabular}{|c|c|c|c|c|c|c|c|}
\hline \multirow[t]{3}{*}{ Variabel } & \multicolumn{4}{|c|}{ Kepuasan Pasien Rawat Jalan } & \multicolumn{2}{|c|}{ Total } & \multirow[t]{3}{*}{ p-value } \\
\hline & \multicolumn{2}{|c|}{ Puas } & \multicolumn{2}{|c|}{ Tidak Puas } & \multirow[b]{2}{*}{$\mathbf{n}$} & \multirow[b]{2}{*}{$\%$} & \\
\hline & $\mathbf{n}$ & $\%$ & $\mathbf{n}$ & $\%$ & & & \\
\hline \multicolumn{8}{|l|}{ Reliability } \\
\hline Baik & 30 & 58,8 & 21 & 41,2 & 51 & 100 & 0,001 \\
\hline Tidak Baik & 11 & 24,2 & 34 & 75,6 & 45 & 100 & \\
\hline \multicolumn{8}{|l|}{ Responseivenes } \\
\hline Baik & 31 & 55,4 & 25 & 44,6 & 56 & 100 & 0,006 \\
\hline Tidak Baik & 10 & 25 & 30 & 75 & 40 & 100 & \\
\hline \multicolumn{8}{|l|}{ Assurance } \\
\hline Baik & 23 & 60,5 & 15 & 39,5 & 38 & 100 & 0,008 \\
\hline Tidak Baik & 18 & 31 & 40 & 69 & 59 & 100 & \\
\hline \multicolumn{8}{|l|}{ Empathy } \\
\hline Baik & 22 & 61,1 & 14 & 38.9 & 36 & 100 & 0,009 \\
\hline Tidak Baik & 19 & 31,7 & 41 & 68,3 & 60 & 100 & \\
\hline \multicolumn{8}{|l|}{ Tangible } \\
\hline Baik & 22 & 66,7 & 11 & 33,3 & 33 & 100 & 0,001 \\
\hline Tidak Baik & 19 & 30.2 & 44 & 69,8 & 63 & 100 & \\
\hline Total & 41 & 42,7 & 55 & 57,3 & 96 & 100 & \\
\hline
\end{tabular}

\section{PEMBAHASAN}

\section{Hubungan Reliability (Kehandalan) Dengan Kepuasan Pasien Rawat Jalan di Puskesmas Batumandi Kabupaten Balangan Tahun 2021}

Berdasarkan hasil penelitian menunjukkan bahwa sebagian besar responden menyatakan baik terhadap reliability (kehandalan) yaitu sebanyak 51 responden $(53,1 \%)$. Hal ini dapat dilihat pada banyaknya responden yang menjawab setuju pada pernyataan nomor 1 yaitu sebanyak 78 responden $(81,3 \%)$ dengan poin pertugas memberikan informasi tentang jalur pelayanan bagi pasien yang datang ke Puskesmas. Hal tersebut dikarenakan responden merasa informasi yang diberikan oleh petugas kesehatan mengenai jalur pelayanan yang diberikan oleh petugas kesehatan dapat dipercaya atau handal sesuai dengan apa yang telah dijanjikan kepada responden.

Berdasarkan hasil penelitian menunjukkan bahwa proporsi pasien yang puas dengan reliability (kehandalan) baik sebanyak 58,8\% lebih besar dari proporsi pasien yang puas dengan reliability (kehandalan) tidak baik sebanyak 24,4\%. Dan dari proporsi pasien yang tidak puas dengan reliability (kehandalan) tidak baik sebanyak 75,6 \% lebih besar dari proporsi pasien yang tidak puas dengan reliability (kehandalan) baik sebanyak 41,2 \%. Berdasarkan hasil uji statistik menunjukkan bahwa nilai Continuity Correction dengan $p$-value $=0,001(p$ value $\leq 0,05)$ maka Ho ditolak dan Ha diterima artinya ada hubungan yang signifikan antara reliability (kehandalan) dengan kepuasan rawat jalan di Puskesmas Batumandi.

Penelitian Sulastri (2021), menunjukkan hasil yang sama yaitu ada hubungan antara dimensi mutu realibility dengan kepuasan pasien. Hal ini menegaskan bahwa untuk mencapai aspek dimensi kehandalan (realibility) setiap tenaga kesehatan harus melaksanakan pelayanan sesuai dengan rencana, memiliki kepedulian dalam pelayanan terhadap permasalahan yang dialami, handal dalam menyampai kan informasi, dan akurat dalam pelayanan. Jika hal tersebut dapat diberikan kepada pasien, maka akan meningkatkan kepuasan pelayanan pada pasien (6).

Hubungan Responsiveness (Ketanggapan) Dengan Kepuasan Pasien Rawat Jalan di Puskesmas Batumandi Kabupaten Balangan Tahun 2021 
Berdasarkan hasil penelitian menunjukkan bahwa sebagian besar responden menyatakan baik terhadap responsiveness (ketanggapan) yaitu sebanyak 56 responden (58,3\%). Hal ini dapat dilihat pada banyaknya responden yang menjawab setuju pada pernyataan nomor 2 yaitu sebanyak 80 responden $(83,3)$ dengan poin petugas menjawab dengan cepat dan tanggap saat melayani setiap keluhan pasien. Hal tersebut dikarenakan adanya keinginan petugas kesehatan membantu para responden dengan cepat dan tanggap.

Berdasarkan hasil penelitian menunjukkan bahwa proporsi pasien yang puas dengan responsiveness (kehandalan) baik sebanyak 55,4\% lebih besar dari proporsi pasien yang puas dengan responsiveness (kehandalan) tidak baik sebanyak 25 $\%$. Dan dari proporsi pasien yang tidak puas dengan responsiveness (kehandalan) tidak baik sebanyak $75 \%$ lebih besar dari proporsi pasien yang tidak puas dengan responsiveness (kehandalan) baik sebanyak $44,6 \%$. Berdasarkan hasil uji statistik menunjukkan bahwa nilai Continuity Correction dengan $p$-value $=0,006$ ( $p$-value $\leq 0,05)$ maka Ho ditolak dan Ha diterima artinya ada hubungan yang signifikan antara responsiveness (ketanggapan) dengan kepuasan rawat jalan di Puskesmas Batumandi. Penelitian yang dilakukan oleh Saputra dkk (2019), telah berhasil membuktikan bahwa bagi pemakai jasa pelayanan kesehatan lebih terkait dengan dimensi ketanggapan petugas dalam memenuhi kebutuhan pasien, kelancaran komunikasi petugas dengan pasien, keramahtamahan petugas dalam melayani pasien dan atau kesembuhan peyakit yang dideritannya (7).

\section{Hubungan Assurance (Jaminan) Dengan Kepuasan Pasien Rawat Jalan di Puskesmas Batumandi Kabupaten Balangan Tahun 2021}

Berdasarkan hasil penelitian menunjukkan bahwa sebagian besar responden menyatakan tidak baik terhadap assurace (jaminan) yaitu sebanyak 58 responden $(60,4 \%)$. Hal ini dapat dilihat pada banyaknya responden yang menjawab setuju pada pernyataan nomor 3 yaitu sebanyak 84 responden $(87,5 \%)$ dengan poin petugas tidak ramah dalam melakukan pelayanan kesehatan. Hal ini dikarenakan kurangnya kemampuan dari beberapa petugas dalam menumbuhkan rasa percaya dari responden salah satunya dengan memberikan pelayanan yang ramah dan sopan kepada responden sehingga responden merasa nyaman dan yakin terhadap pelayanan yang akan dilakukan (8).

Berdasarkan hasil penelitian menunjukkan bahwa proprsi pasien yang puas dengan assurance (jaminan) baik sebanyak 60,5 \% lebih besar dari proporsi pasien yang puas dengan assurance (jaminan) tidak baik sebanyak $31 \%$. Dan dari proporsi pasien yang tidak puas dengan assurance (jaminan) tidak baik sebanyak 69\% lebih besar dari proporsi pasien yang tidak puas dengan assurance (jaminan) baik sebanyak 39,5\%. Berdasarkan hasil uji statistik menunjukkan bahwa nilai Continuity Correction dengan $p$-value $=0,008$ ( $p$-value $\leq 0,05$ ) maka Ho ditolak dan Ha diterima artinya ada hubungan yang signifikan antara assurance (jaminan) dengan kepuasan rawat jalan di Puskesmas Batumandi.

\section{Hubungan Empathy (Perhatian) Dengan Kepuasan Pasien Rawat Jalan di Puskesmas Batumandi Kabupaten Balangan Tahun 2021}

Berdasarkan hasil penelitian menunjukkan bahwa sebagian besar responden menyatakan tidak baik terhadap empathy (perhatian) yaitu sebanyak 60 respnden $(62,5 \%)$. Hal ini dapat dilihat pada banyaknya responden yang menjawab setuju pada pernyataan nomor 4 yaitu sebanyak 88 responden $(91,7 \%)$ dengan poin petugas memberikan perhatian khsusus secara pilih-pilih. Hal ini karena kurangnya rasa kepedulian dan perhatian khusus oleh petugas kesehatan kepada pasien secara merata tanpa membedakan status, penampilan bahkan ikatan kekeluargaan.

Berdasarkan hasil penelitian menunjukkan bahwa proporsi pasien yang puas dengan empathy (perhatian) baik sebanyak 61,1\% lebih besar dari proporsi pasien yang puas dengan empathy (perhatian) tidak baik sebanyak 31,7\%. Dan dari proporsi pasien yang tidak puas dengan empathy (perhatian) tidak baik sebanyak 68,3\% lebih besar dari proporsi pasien yang tidak puas dengan empathy (perhatian) baik sebanyak 38,9\%. Berdasarkan hasil uji statistik menunjukkan bahwa nilai Continuity Correction dengan $p$-value $=0,009(p$ value $\leq 0,05$ ) maka Ho ditolak dan Ha diterima artinya ada hubungan yang signifikan antara 
empathy (perhatian) dengan kepuasan rawat jalan di Puskesmas Batumandi. Berdasarkan teori yang mendukung penelitian ini dimana dimensi empati sangat berhubungan dengan kepuasan pasien karena empati perawat dapat membantu dalam kesembuhan pasien (9)

Hubungan Tangible (Bukti fisik/bukti langsung) Dengan Kepuasan Pasien Rawat Jalan di Puskesmas Batumandi Kabupaten Balangan Tahun 2021

Berdasarkan hasil penelitian menunjukkan bahwa sebagian besar responden menyatakan tidak baik terhadap tangible (bukti fisik/bukti langsung) yaitu sebanyak 63 respnden $(65,6 \%)$. Hal ini dapat dilihat pada banyaknya responden yang menjawab setuju pada pernyataan nomor 4 yaitu sebanyak 83 responden $(86,5 \%)$ dengan poin lahan parkir dan tempat duduk diruang tunggu tidak memadai. Berdasarkan hasil penelitian menunjukkan bahwa proporsi pasien yang puas dengan tangible (bukti fisik/bukti langsung) baik sebanyak 66,7 \% lebih besar dari proporsi pasien yang puas dengan tangible (bukti fisik/bukti langsung) tidak baik sebanyak 30,2 \%. Dan dari proporsi pasien yang tidak puas dengan tangible (bukti fisik/bukti langsung) tidak baik sebanyak $69,8 \%$ lebih besar dari proporsi pasien yang tidak puas dengan tangible (bukti fisik/bukti langsung) baik sebanyak $33,3 \%$. Berdasarkan hasil uji statistik menunjukkan bahwa nilai Continuity Correction dengan $p$-value $=$ 0,001 (p-value $\leq 0,05$ ) maka Ho ditolak dan Ha diterima artinya ada hubungan yang signifikan antara tangible (bukti fisik/bukti langsung) dengan kepuasan rawat jalan di Puskesmas Batumandi.

Bukti fisik juga penting karena dapat mempengaruhi kepercayaan pasien dalam pelayanan kesehatan. Atribut dari dimensi ini berkaitan erat dengan lingkungan yang asri,kebersihan ruangan, kerapihan petugas, Asesibilitas, ketersediaan fasilitas (tempat duduk, perlengkapan medis), dan alur pelayanan yang jelas (10).

\section{KESIMPULAN}

Berdasarkan kesimpulan pada penelitian ini adalah terdapat hubungan antara reliability, responsiveness (kehandalan), ketanggapan, assurance (jaminan), empathy (perhatian) dan tangible (bukti fisik/bukti langsung) dengan kepuasan pasien rawat jalan di Puskesmas Batumandi Kabupaten Balangan tahun 2021.

\section{DAFTAR PUSTAKA}

1. Saraswati. 2020. Rencana Aksi Kegiatan Direktorat Pelayanan Kesehatan Primer 2020-2024. Jakarta: Direktorat Pelayanan Kesehatan Primer

2. Bustami. 2011. Penjamin Mutu Pelayanan Kesehatan dan Akseptabilitasnya. Jakarta: Erlangga.

3. Nursalam. 2014. Manajemen Keperawatan Aplikasi dalam Praktik Keperawatan Profesional Edisi 4. Jakarta : Salemba Medika.

4. Peraturan Menteri Pendayagunaan Aparatur Negara dan Reformasi Birokrasi RI No. 14 Tahun 2017 tentang Pedoman Penyusunan Survei Kepuasan Masyarakat terhadap Penyelenggaraan Pelayanan Publik.

5. Peraturan Menteri Kesehatan Republik Indonesia Nomor 75. 2014. Pusat Kesehatan Masyarakat. 2014. Jakarta : Menkes RI

6. Sulastri dkk. 2021. Hubungan antara mutu pelayanan kesehatan dengan Kepuasan pasien rawat jalan di puskesmas lurasik Kabupaten timor tengah utara. Jurnal pazih_pergizi pangan DPD NTT. Vol. 10(2)2021.

7. Saputra, Adisurya dan Ariani Nurlitas. 2019. Hubungan Mutu Pelayanan Kesehatan Dengan Kepuasaan Pasien Rawat Jalan Pengguna Kartu Bpjs Di Rumah Sakit Daerah Idaman Kota Banjarbaru. Borneo Nursing Journal (BNJ). Vol.1(1) 2019. Akper Yarsis.

8. Azwar, Azrul, 2008, Pengantar Administrasi Kesehatan, Jakarta, Binaputra

9. Cunlaka, poramaphon, internasional patients satisfaction toward nurses sevice quality 2010.

10. Jayanti, N. D. 2016. Kualitas pelayanan (Reliability, responsiveness, assurance, emphaty tangibles) di leged premium coffee. Diakses pada tanggal 5 Januari 2020. . 